\title{
Can nursery schools help prevent childhood obesity?
}

\author{
L. A. McSweeney ${ }^{1}$, C. D. Summerbell ${ }^{2}$, T. Rapley ${ }^{1}$ and A. J. Adamson ${ }^{1}$ \\ ${ }^{1}$ Institute of Health and Society, Newcastle University, NE2 4HH, UK and ${ }^{2}$ School of Medicine and Health, \\ Durham University, TS17 6BH, UK
}

In $2009 / 10,23.1 \%$ of children in reception were identified as overweight or obese $(\mathrm{OW})^{(1)}$. OW 2-5-year-olds are four times more likely to become OW adults ${ }^{(2)}$. It is proposed that 'early childhood provides a unique opportunity within which to establish lifestyle behaviours that will promote health and minimise the risk of development of fatness ${ }^{(3)}$. There is a paucity of interventions aimed at preventing childhood OW in preschool settings.

Ongoing work seeks to determine strategies, which aim to prevent $\mathrm{OW}$ in children that are acceptable to nursery practitioners (NP) and parents. Factors that influence children's lifestyle behaviours, which may be amenable to change, have been explored. NP ( $n$ 17) in five preschool centres in North East England were interviewed to elicit their views with regard to OW-related behaviours and current nursery healthy lifestyle practices. Parents ( $n$ 15) whose children attended the centres were asked, by means of a mapping activity, to describe their child's dietary and physical activity patterns (Fig. 1).

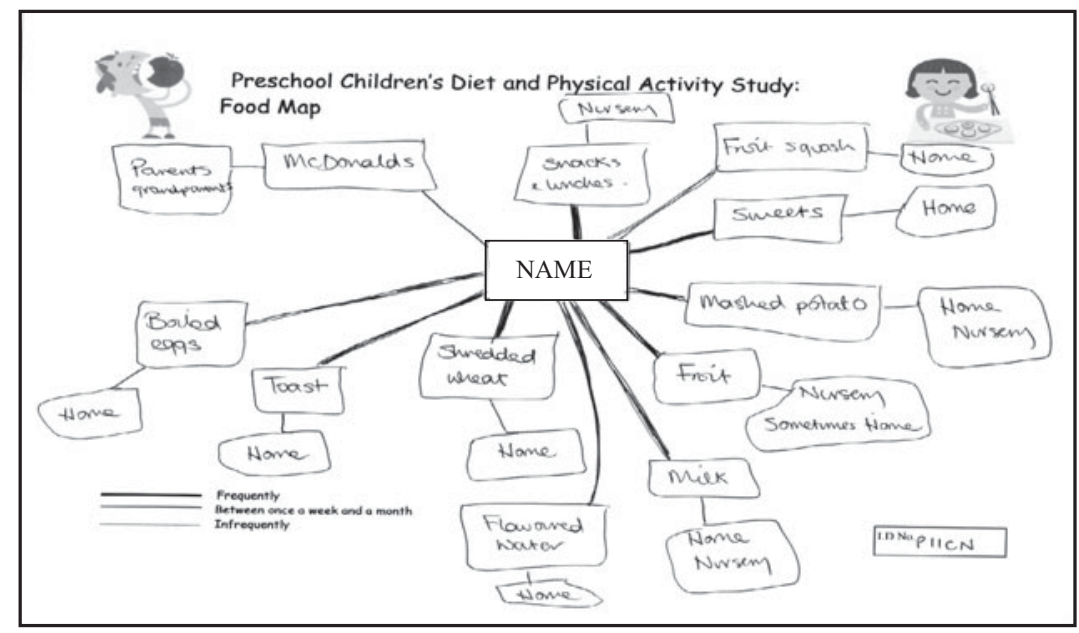

Analysis of qualitative data revealed complex communication and practical issues between the NP and parents. Staff were keen to report that they did not directly blame parents for 'unhealthy' behaviours within the families; however, underlying messages from other comments suggested otherwise: 'I'm sure if they just stuck to their guns and said ... no, we're not going to McDonalds ... they will just give in for peace and quiet' (NP). Giving parents practical advice or education was a recurrent theme from staff: 'There are young parents who don't know ... who need parenting skills on how to feed their children properly ... they've got to be taught how' (NP). Mixed messages were sometimes inadvertently given to parents regarding current nursery practices, such as allowing the provision of sweets and cakes for special occasions. As expected 'home' and 'nursery' were the main sources of food for the 3-4-year-olds and the 'garden' was where most children were likely to be active.

The issues raised from these initial data will be further explored in focus groups to determine interventions that may be acceptable to both NP and parents and how best they can be implemented to encourage healthy lifestyle behaviours in preschool children and their families.

Lorraine McSweeney is funded by an ESRC studentship awarded to Fuse, the Centre for Translational Research in Public Health. Fuse is a UKCRC Public Health Research Centre of Excellence, supported by ESRC, MRC, NIHR, BHF and CRUK.

1. The NHS Information Centre Lifestyles Statistics (2010) National Child Measurement Programme: England 2009/10 school year: Department of Health; December 2010

2. Olstad DL \& McCargar L (2009) Prevention of overweight and obesity in children under the age of 6 years. Appl Physiol Nutr Metab 34(4), 551-570.

3. Campbell KJ \& Hesketh KD (2007) Strategies which aim to positively impact on weight, physical activity, diet and sedentary behaviours in children from zero to five years. A systematic review of the literature. IASO - Obes Rev 8, 327-338. 